J. Amer. Sot. Hort. SCI. 117(1):169-173. 1992.

\title{
Six New Somatic Citrus Hybrids and Their Potential for Cultivar Improvement
}

\author{
Jude W. Grosser, Frederick G. Gmitter, Jr., Franca Sesto, Xiu Xin Deng, and J.L. Chandler \\ Department of Fruit Crops, Citrus Research and Education Center University of Florida, Institute \\ of Food and Agricultural Sciences, 700 Experiment Station Road, Lake Alfred, FL 33850
}

Additional index words. plant breeding, polyploidy, protoplasm fusion, rootstock, scion, triploid

\begin{abstract}
Protoplasm culture following polyethylene glycol (PEG) -induced fusion resulted in the regeneration of somatic hybrid plants from the following six parental combinations: Citrus sinermis (L.) Osbeck Cv. Hamlin + Severinia buxifolia (Poir.) Tenore (Chinese box-orange); C. reticulate Blanco CV. Cleopatra + Poncirus trifoliata (L.) Raf. CV. Flying Dragon; C. reticulate CV. Cleopatra + Swingle citrumelo (C. paradisi Macf. $\times$ P. trifoliata); $C$. sinensis $C V$. Hamlin + C. jambhiri $C V$. Rough lemon; C. sinensis $C V$. Valencia + C. jambhiri $C V$. Rough lemon; and C. paradisi $C V$. Thompson + 'Murcott' tangor (purported hybrid of $C$. reticulate $\mathrm{x} C$. sinensis). Diploid plants were regenerated from nonfused embryogenic culture-derived protoplasts of 'Cleopatra' mandarin and 'Hamlin' and 'Valencia' sweet orange, and from nonfused leaf-derived protoplasts of Rough lemon and 'Mnrcott'. Regenerated plants were classified according to leaf morphology, chromosome number, and isozyme analyses. All of the somatic hybrids reported herein are tetraploid $(2 \mathrm{n}=4 \mathrm{x}=36)$, with the exception of the 'Hamlin' $+S$. buxifolia hybrid, which was unexpectedly found to have a chromosome number of $2 n=27$. These six new somatic hybrids have potential in citrus scion and rootstock improvement for commercial use.
\end{abstract}

Techniques for producing somatic hybrids of Citrus by protoplasm fusion are well developed, and strategies for applying the techniques to citrus scion and rootstock improvement have been outlined (Grosser and Gmitter, 1990a, 1990b, 1990c). Numerous citrus somatic hybrids have been reported, including interspecific combinations (Grosser et al., 1989; Kobayashi et al., 1988a, 1988b; Ohgawara et al., 1989; Tusa et al., 1990), intergeneric combinations between sexually compatible species (Deng et a., 1991; Grosser and Gmitter 1990a, 1990b, 1990c; Grosser et al., 1988a; Ohgawara et al., 1985), and intergeneric combinations between sexually incompatible species (Grosser and Gmitter, 1990a, 1990b, 1990c Grosser et al., 1988b, 1990). Citrus somatic cybrids have also been reported (Vardi et al., 1987, 1989).

One strategy for citrus rootstock improvement is the production of hybrids that combine Citrus species with graft-compatible, but sexually incompatible, related genera that possess traits of interest (Grosser and Gmitter, 1990a, 1990b, 1990c). Citrus relatives represent a largely untapped reservoir of genetic diversity, but, in general, are horticulturally unacceptable for direct use as citrus rootstock (Swingle and Reece, 1967). Somatic hybridization with Citrus could minimize or eliminate problems of inadequate horticultural performance. Previously, we have reported on the production of somatic hybrid plants from three such parental combinations: Citrus sinensis cv. Hamlin + Severinia disticha (Blanco) Swing. (Grosser et al., 1988b); Citrus sinensis CV. Hamlin + Citropsis gilletiana Swingle \& M. Kel. (Grosser and Gmitter, 1990c); and Citrus reticulate + Citropsis gilletiana (Grosser et al., 1990). The attempted somatic hybridization of Citrus sinensis cv. Hamlin $+S$. buxifolia is another example of efforts to apply this strategy. Severinia buxifolia possesses several traits desirable for rootstock improvement, including cold hardiness, salt and B tolerance (Cooper, 1961), and resistance to Phytophthoru (Hutchison and Grimm, 1973;

Received for publication 17 May 1991. Accepted for publication 10 Sept. 1991. Florida Agricultural Experiment Station Journal Series no. R-01587. We thank X.B. Ling, S. Huang, D.C. Chen, and N. Tusa for technical assistance. The cost of publishing this paper was defrayed in part by the payment of page charges. Under postal regulations, this paper therefore must be hereby marked advertisement solely to indicate this fact.
Graham, 1990) and the citrus (Tylenchulus semipenetrans Cobb.) and burrowing (Radopholus citrophilus Huettel, Dickson \& Kaplan) nematodes (Hutchison and O'Bannon, 1972).

A second strategy for citrus rootstock improvement is the production of somatic hybrids from existing complementary germplasm (Grosser and Gmitter, 1990a, 1990b). The attempted somatic hybridizations of Cleopatra mandarin + Swingle citrumelo, Cleopatra mandarin + Flying Dragon trifoliate orange, 'Valencia' sweet orange + Rough lemon, and 'Hamlin' sweet orange + Rough lemon represent efforts in this direction. Cleopatra mandarin is an important rootstock in Florida and elsewhere because it is cold-hardy, resistant to citrus tristeza virus, and moderately tolerant of citrus blight (Castle, 1987). Trees grafted on Cleopatra are moderately vigorous but are susceptible to foot and root rot (caused by Phytophthora parasitic Dast.) (Graham, 1990) and are not precocious. Size of fruit from Cleopatra trees is often inadequate for the fresh-fruit market. The Cleopatra + Swingle citrumelo and Cleopatra + Flying Dragon somatic hybrids (Table 1) have the potential to compensate for some of the deficiencies of Cleopatra via complementation. Both Swingle and Flying Dragon are resistant to $P$. parasitic. Flying Dragon can positively influence scion precocity and cold hardiness and has potential for reducing tree size (Castle, 1987). Reduced tree size is of interest for high-density plantings to increase productivity and the effectiveness of cold protection methods and reduce harvesting costs. The Swingle parentage may have a positive influence on fruit size.

Somatic hybridization of 'Valencia' + Rough lemon and 'Hamlin' + Rough lemon was attempted to generate vigorous rootstock with improved cold hardiness and tolerance to citrus blight from Citrus sinensis (sweet orange). Citrus blight is considered the most significant pathological problem of citrus in Florida and Brazil (Derrick et al., 1990). Vigorous rootstock, such as Rough lemon (Citrus jambhiri Lush), Volkamer lemon (C. volkameriana Ten. \& Pasq.), Rangpur lime (C. limonia Osbeck), and Palestine sweet lime (C. limettioides Tan.), enjoyed great popularity in Florida in the past, but their suscep-

Abbreviations: PEG, polyethylene glycol; PER, peroxidase; PGI, phosphoglucose isomerase; PGM, phosphoglucomutase. 
Table 1. Citrus plants regenerated following protoplasm fusion.

\begin{tabular}{|c|c|c|c|c|}
\hline Embryogenic parent & Leaf parent & $\begin{array}{c}\text { Somatic } \\
\text { hybrid plants }\end{array}$ & $\begin{array}{l}\text { Plants from } \\
\text { embryogenic } \\
\text { parent }\end{array}$ & $\begin{array}{l}\text { Plants from } \\
\text { leaf parent }\end{array}$ \\
\hline C. sinensis 'Hamlin'y & S. buxifoliax & 56 & 0 & 0 \\
\hline C. reticulata Cleopatraw & P. trifoliata Flying Dragon & 164 & 3 & 0 \\
\hline C. reticulata Cleopatraw & Swingle citrumelo & 204 & 2 & 0 \\
\hline C. sinensis 'Valencia'y & C. jambhiri Rough lemon & 11 & 1 & 3 \\
\hline C. sinensis 'Hamlin'y & C. jambhiri Rough lemon & 12 & 19 & 10 \\
\hline C. paradisi 'Thompson'w & 'Murcott' tangor & 19 & 0 & 28 \\
\hline
\end{tabular}

${ }^{2}$ The total number of plants recovered, not necessarily the number of plants regenerated from individual fusion events.

yEmbryogenic suspension culture.

'Nonembryogenic callus culture inste:

"Embryogenic callus culture.

tibility to "cold and blight has reduced their use considerably (Castle, 1987).

One strategy for the application of somatic hybridization to citrus scion improvement involves the development of allotetraploid breeding parents via somatic hybridization for use in diploid $\times$ tetraploid hybridizations to generate seedless triploid hybrids. Soost and Cameron (1969) have previously demonstrated that triploid hybrids are seedless yet capable of being fruitful. Tangors (sweet orange $\mathrm{x}$ mandarin hybrids) and tangelos (grapefruit $\times$ mandarin hybrids) are important fresh fruit citrus vaneties grown and consumed internationally (Saunt, 1990). However, most cultivars within these groups are seedy, and the development of improved seedless cultivars is an important breeding objective. The attempted somatic 'hybridization of Citrus paradisi 'Thompson' + 'Murcott' tangor represents our initial efforts to develop quality tetraploid breeding parents.

\section{Materials and Methods}

Protoplasm isolation. Protoplasts of Flying Dragon, Swingle citrumelo, Rough lemon, and 'Murcott' were isolated from leaves of young nucellar seedlings maintained in a growth chamber (16-h photoperiod, $300 \mu \mathrm{mol} \cdot \mathrm{m}^{-2} \cdot \mathrm{s}^{-1}$ light intensity, 26 to $30 \mathrm{C}$ ) according to the procedure of Grosser and Chandler (1987). Protoplasts of S. buxifolia were isolated from a seedling-derived, nonembryogenic friable callus culture initiated and maintained on Murashige and Tucker (1969) basal medium containing (on a per liter basis) $0.55 \mathrm{mg}$ 2,4-dichlorophenoxyacetic acid (2,4-D), $0.22 \mathrm{mg}$ kinetin, $20 \mathrm{ml}$ coconut $\mathrm{H}_{2} \mathrm{O}$ (Gibco Labs, Grand Island, N.Y.), and $50 \mathrm{~g}$ sucrose (designated MTC), according to Grosser and Gmitter (1990a). Protoplasts of Citrus sinensis CV. Hamlin, C. sinensis CV. Valencia, Citrus reticulate cv. Cleopatra, and Citrus paradisi cv. Thompson were isolated from nucellar-derived habituated embryogenic callus cultures maintained on either liquid or semisolid EME or $\mathrm{H}+\mathrm{H}$ medium, as described by Grosser and Gmitter (1990a). In most cases, protoplasts were further purified by centrifugation on a 25\% sucrose-13\% mannitol gradient (Tusa et al., 1990; Grosser and Gmitter, 1990a).

Protoplasm fusion and culture. We generally produced the somatic hybrids by chemically inducing fusion of totipotent Citrus protoplaits, isolated from embryogenic cultures of one parent, with protoplasts isolated from seedling leaves or nonembryogenic callus cultures of the second parent (see Table 1). About equal volumes of purified protoplasts from each parental combination were mixed and fused using the modified polyethylene (PEG) method of Menczel et al. (1981) as described by Grosser and Gmitter (1990a). The 'Hamlin' $+S$. buxifolia and 'Thompson' + 'Murcott' somatic hybrids were generated using 8000 M.W. PEG (Sigma, St. Louis), but the other hybrids were generated using 1500 M.W. PEG (Aldrich, Milwaukee). The latter has been shown to provide excellent results in somatic fusion experiments (Chand et al., 1988).

After fusion, protoplasts were cultured directly in fusion dishes (60 x $15 \mathrm{~mm}$; Falcon, Lincoln Park, N.J.) in eight to 20 drops of either BH3 protoplasm culture medium, EME protoplasm culture medium, or a $1 \mathrm{BH} 3: 1 \mathrm{EME}$ medium (v/v), as described by Grosser and Gmitter (1990a). Osmoticum reduction, embryo enlargement, embryo germination, in vitro rooting, and plantlet acclimation were carried out as described by Grosser and Gmitter (1990a).

Cytology. Chromosome numbers of mitotically active root and leaf meristem cells from regenerated plants were determined using modifications of the hematoxylin staining protocol of Sass (1958) as described by Tusa et al. (1990) for roots and Gmitter et al. (1990) for leaves. A minimum of three cells per plant for three somatic hybrid plants from each parental combination were examined.

Electrophoresis of leaf isozymes. Leaf isozymes were separated in mixed starch $(10 \%)$ and agarose $(0.15 \%)$ gels with the pH 5.7 histidine-citrate buffer of Cardy et al. (1981). A constant $60 \mathrm{~mA}$ current was run through the gels for $3 \mathrm{~h}$ at $4 \mathrm{C}$. Gels were sliced and stained for the activity of peroxidase (PER, E. C.1.11.1.7), phosphoglucomutase (PGM, E. C.2.7.5.1), and phosphoglucose isomerase (PGI, E. C.5.3.1.9). All isozyme analyses were repeated at least three times to ensure accurate interpretation.

\section{Results and Discussion}

The pedigrees of plants recovered after protoplasm fusion and culture are summarized in Table 1 . Somatic hybrid plant recovery was generally of equal or greater efficiency than plant recovery from unfused parental protoplasts. In all cases, somatic hybrid leaf morphology was intermediate to that of the parents (Fig. 1). No morphological variability was observed in any of the somatic hybrid populations. Plant recovery was more efficient from nonfused 'Hamlin' protoplasts isolated from embryogenic callus cultures than from embryogenic suspension cultures. Only a few plants were regenerated from nonfused Cleopatra protoplasts isolated from an embryogenic callus culture. Somatic hybrid embryo proliferation was evident during culture for both the Cleopatra + Flying Dragon and Cleopatra + Swingle somatic hybrids, contributing to the large number of plants regenerated.

An unexpected result was the recovery of Rough lemon and 'Murcott' plants from nonfused leaf protoplasts. Recently, plants were regenerated from nonfused leaf protoplasts of 'Femmi- 


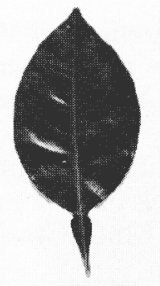

a

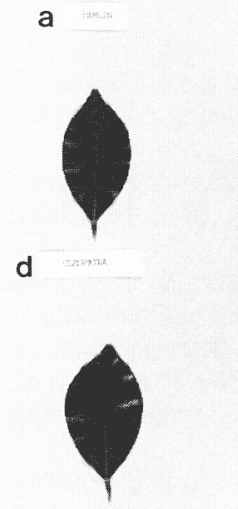

g

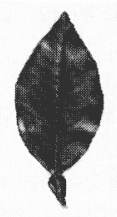

j

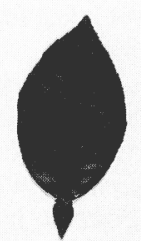

m

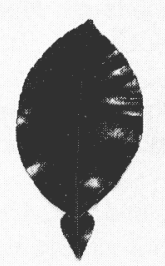

p

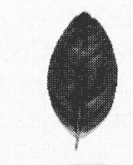

b

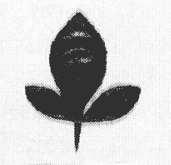

e

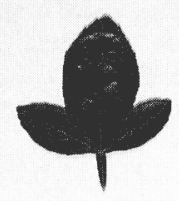

h

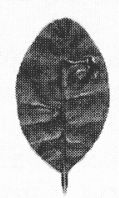

k



n

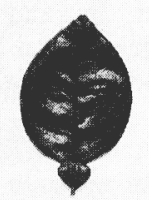

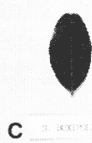

c

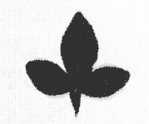

f

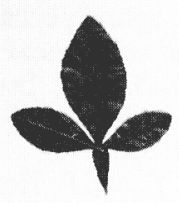

i

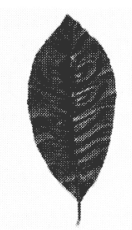

I
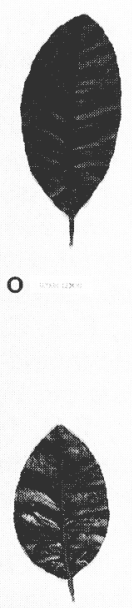

r
Fig. 1. Leaf morphology of: (a, m) 'Hamlin' sweet orange, (h) 'Hamlin' sweet orange + Severinia buxifolia somatic hybrid, (c)S. buxifolia, (d, g) Cleopatra mandarin, (e) Cleopatra + Flying Dragon trifoliate orange somatic hybrid, (f) Flying Dragon, (h) Cleopatra + Swingle citrumelo somatic hybrid, (i) Swingle, (j) 'Valencia' sweet orange, (k) 'Valencia' sweet orange + Rough lemon somatic hybrid, (l, o) Rough lemon, (n) 'Hamlin' + Rough lemon somatic hybrid, (p) 'Thompson' grapefruit, (q) 'Thompson' + 'Murcott' tangor somatic hybrid, (r) 'Murcott'.

nello' lemon (Tusa et al., 1990), 'Marsh' grapefruit (Ohgawara et al., 1989), and 'Duncan' grapefruit (J.W.G., unpublished data). These results indicate that future research requiring protoplasm for plant regeneration will not necessarily be limited to genotypes capable of producing nucellar-derived friable embryogenic callus cultures.

Chromosome counts revealed that, with the exception of the 'Hamlin' $+S$. buxifolia somatic hybrid plants, all of the examined somatic hybrid plants were tetraploid $(2 \mathrm{n}=4 \mathrm{x}=36)$, as expected. All 10 of the 'Hamlin' $+S$. buxifolia plants examined from the population of 56 morphologically uniform somatic hybrids, including plants recovered from separate fusion petri dishes, were found to have a chromosome number of $2 \mathrm{n}$ $=27$ (Fig. 2). Information from efforts to determine whether these plants were true triploids $(2 \mathrm{n}=3 \mathrm{x}=27)$ or aneuploids $(2 \mathrm{n}=27)$ was suggestive, but "not conclusive." True triploidy could have resulted from haploid + diploid cell fusion or from single genome elimination. However, attempts to determine the chromosome number of the parental 'Hamlin' suspension culture and the $S$. buxifolia callus line were unsuccessful. The $S$. buxifolia callus line may have been at the haploid level at the time of protoplasm isolation. This callus line was grown with a high level of 2,4-D, a synthetic auxin associated with chromosome number instability in other plant tissue culture systems (Nickell and Torrey, 1969; Torrey, 1977). It is unlikely that the 'Hamlin' suspension culture was haploid, because three other tetraploid somatic hybrids were generated using protoplasts of this same line (Grosser and Gmitter, 1990c). Aneuploidy could have resulted from random or specific chromosome elimination. Chromosome elimination has not been reported in any other Citrus somatic hybrids, including tetraploid somatic hybrid plants regenerated from fusions of 'Hamlin' with $S$. disticha (Grosser et al., 1988b), but random chromosome elimination has been reported in fusion products of extremely wide intergeneric parental combinations (Gleba and Hoffman, 1978; Kao, 1977). Random chromosome elimination presumably induced by gamma irradiation has been reported in somatic hybrid plants (Agoudgil et al., 1990; Wijbrandi et al., 1990). It both parental callus lines were indeed diploid at the time of protoplasm fusion, the fact that all of the 'Hamlin' + S. buxifolia somatic hybrid plants examined were morphologically uniform with a chromosome number of $2 n=27$, including plants regenerated from separate fusion events, suggests specific chromosome elimination. If chromosome elimination was random, plants with variable chromosome counts and morphology should have been observed.

Complementarily of parental band patterns was observed among the somatic hybrids (Fig. 3). PGM and PER are monomeric enzymes, and somatic hybrids produced only those bands found in both parents. PGI is a dimeric enzyme; the 'Thompson'

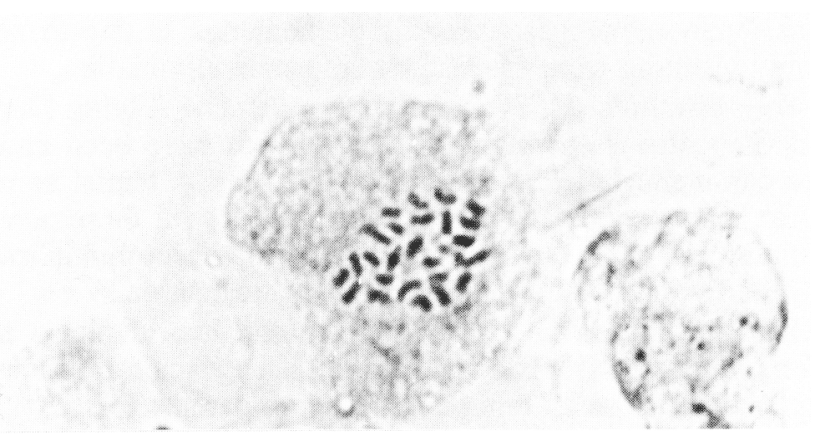

Fig. 2. Root tip squash prepared from a 'Hamlin' + Severinia buxifolia somatic hybrid, showing a chromosome number of $2 n=27$ ( $\times 900$, oil immersion). 


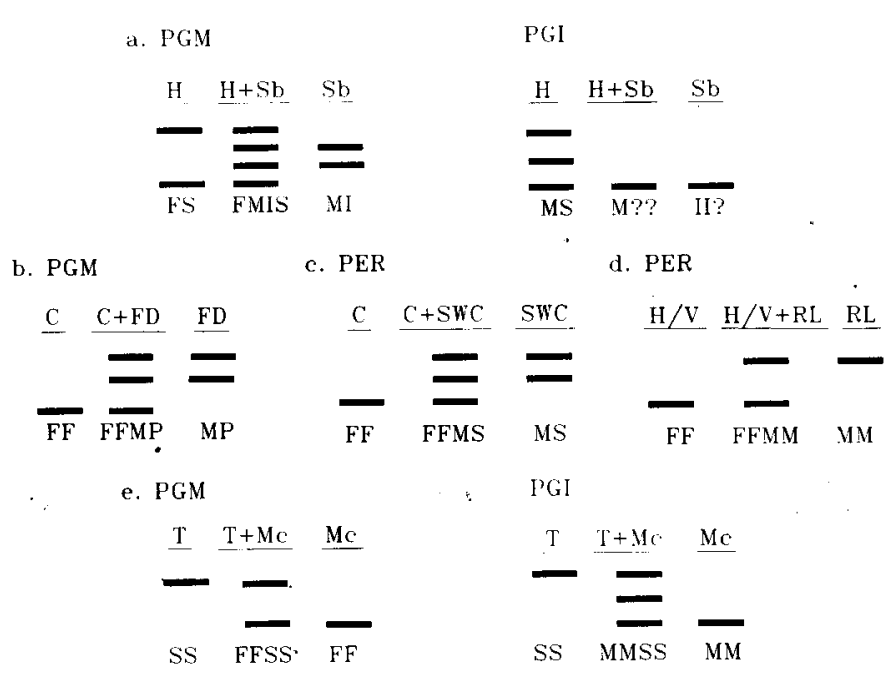

Fig. 3. Schematic diagrams and genotypes of leaf isozyme banding patterns from" parents and somatic hybrids following starch gel electrophoresis: (a) 'Hamlin' (I-I) + Severinia buxifolia (Sb); (b) Cleopatra $(\mathrm{C})$ + Flying Dragon (FD); (c) Cleopatra (C) + Swingle (SWC); (d) 'Hamlin' (H) or 'Valencia' (V) + Rough lemon (RL); (e) 'Thompson' $(\mathrm{T})+$ 'Murcott' $(\mathrm{Me})$. Origin of migration is at top of diagrams.

grapefruit + 'Murcott' tangor hybrid exhibited the heterodimer form (FS) as well as both homodimers (FF and SS, Fig. 3e). Moore and Castle (1988) reported that Swingle citrumelo was FS at the PER locus used in this study. Results of repeated electrophoresis and evaluation of the Cleopatra mandarin + Swingle citrumelo hybrid and parents indicated that the correct genotype for Swingle citrumelo at PER is MS (Fig. 3c).

Isozyme analyses were conducted on 16 of the 'Hamlin' + S. buxifolia somatic hybrid plants and all had identical zymogram profiles. All four parental PGM bands (F, M, I, S) were visible in the zymogram of the 'Hamlin' orange + S. buxifolia hybrid. The zymotype of 'Hamlin' at PGI was MS, and S. buxifolia appeared to be II. The somatic hybrid produced what appeared to be a single band at the M position, although resolution was not sufficient to rule out the possibility that the single band was, in fact, a compressed triplet pattern resulting from the small difference in mobility between the $\mathrm{M}$ and I allele products. These results indicate that the 'Hamlin' chromosome that harbors the $\mathrm{S}$ allele of PGI was lost or the gene was silenced, but all four homologous chromosomes harboring the PGM locus were retained in the somatic hybrid. Therefore, the observed chromosome number $2 \mathrm{n}=27$ probably did not result from the fusion of diploid with haploid protoplasts; rather, isozyme analyses suggest that this phenomenon is due to aneuploidy resulting from specific chromosome elimination.

The 'Hamlin' + S. buxifolia, Cleopatra + Flying Dragon and Cleopatra + Swingle somatic hybrids have been entered into commercial field trials to evaluate their potential as rootstock. Development of propagation methods for these new somatic hybrids via rooted cuttings and in vitro shoot multiplication of each hybrid is required for extensive evaluation.

The 'Thompson' + 'Murcott' somatic hybrid plants have been grafted onto rootstock that may induce scion precocity to expedite their use as tetraploid breeding parents for scion improvement. Diploid 'Murcott' plants regenerated from leaf protoplasts have been grafted onto these rootstock to assess phenotypic stability of mature trees.

\section{Literature cited}

Agoudgil, S., S. Hinnisdaels, A. Mouras, I. Negrutiu, and M. Jacobs 1990. Metabolic complementation for a single gene function associated with partial and total loss of donor DNA in interspecific hybrids. Theor. Appl. Genet. 80:337-342.

Cardy, B. J., C.W. Stuber, and M.M. Goodman. 1981. Techniques for starch gel electrophoresis of enzymes from maize (Zea maize L.). Inst. of Statistics Mimeograph Series 1317, North Carolina State Univ., Raleigh.

Castle, W.S. 1987. Citrus rootstock, p. 361-399. In: R.C. Rom and R.F. Carlson (eds.). Rootstock for fruit crops. Wiley, New York.

Chand, P. K., M.R. Davey, J.B. Power, and E.C. Cocking. 1988. An improved procedure for protoplasm fusion using polyethylene glycol. J. Plant Physiol. 133:480-485.

Cooper, W.C. 1961. Toxicity and accumulation of salts in citrus trees on various rootstock in Texas. Proc. Fla. State Hort. Soc. 74:95104.

Deng, X. X., J.W. Grosser, and F.G. Gmitter, Jr. 1991. Intergeneric somatic hybrid plants from protoplasm fusion of Fortunella crassifolia 'Meiwa' with Citrus sinensis 'Valencia'. Scientia Hort. (In press.)

Derrick, K. S., R.F. Lee, R.H. Brlansky, L.W. Timmer, B.G. Hewitt, and G.A. Barthe. 1990. Proteins associated with citrus blight. Plant Dis. $74: 168-170$.

Gleba, Y.Y. and F. Hoffman. 1978. Hybrid cell line Arabidopsis thaliana and Brassica campestris: No evidence for specific chromosome elimination. Mol. Gen. Genet. 165:257-264.

Gmitter, F. G., Jr., X.B. Ling, and X.X. Deng. 1990. Induction of triploid Citrus plants from endosperm calli in vitro. Theor. Applied Genet. 80:785-790.

Graham, J.H. 1990. Evaluation of tolerance of citrus rootstock to phytophthora root rot in chlamydospore-infested soil. Plant Dis. 74:743-746.

Grosser, J.W. and J.L. Chandler. 1987. Aseptic isolation of leaf protoplasts from Citrus, Poncirus, Citrus $\times$ Poncirus hybrids and Severinia for use in somatic hybridization experiments. Scientia Hort. 31:253-257.

Grosser, J.W. and F.G. Gmitter, Jr. 1990a. Protoplasm fusion and citrus improvement. Plant Breeding Rev. 8:339-374.

Grosser, J.W. and F.G. Gmitter, Jr. 1990b. Wide hybridization of Citrus via protoplasm fusion: Progress, strategies and limitations, p. 31-41. In: A.B. Bennett and S.D. O'Neill (eds.). Horticultural biotechnology, plant biology. vol. 25. Wiley-Liss, New York.

Grosser, J.W. and F.G. Gmitter, Jr. 1990c. Somatic hybridization of Citrus with wild relatives for germplasm enhancement and cultivar development. HortScience 25:147-151.

Grosser, J.W., F.G. Gmitter, Jr., and J.L. Chandler. 1988a. Intergeneric somatic hybrid plants of Citrus sinensis CV. Hamlin and Poncirus trifoliata Cv. Flying Dragon. Plant Cell Rpt. 7:5-8.

Grosser, J. W., F.G. Gmitter, Jr., and J.L. Chandler. 1988b. Intergeneric somatic hybrid plants from sexually incompatible woody species: Citrus sinensis and Severinia disticha. Theor. Applied Genet. 75:397-401.

Grosser, J.W., F.G. Gmitter, Jr., N. Tusa, and J.L. Chandler. 1990. Somatic hybrid plants from sexually incompatible woody species: Citrus reticulate and Citropsis gilletiana. Plant Cell Rpt. 8:656659.

Grosser, J. W., G.A. Moore, and F.G. Gmitter, Jr. 1989. Interspecific somatic hybrid plants from the fusion of 'Key' lime (Citrus aurantifolia) with 'Valencia' sweet orange (Citrus sinensis) protoplasts. Scientia Hort. 39:23-29.

Hutchison, D.J. and G.R. Grimm. 1973. Citrus clones resistant to Phytophthora parasitic: 1973 screening results. Proc. Fla. State Hort. Soc. 86:88-91.

Hutchison, D.J. and J.H. O'Bannon. 1972. Evaluating the reaction of citrus selections to Tylenchulus semipenetrans. Plant Dis. Rpt. 56:747751.

Kao, K.N. 1977. Chromosomal behavior in somatic hybrids of soybean, Nicotiana glauca. Mol. Gen. Genet. 150:355-367. 
Kobayashi, S., K. Fujiwara, I. Oiyama, and S. Ishii. 1988a. Somatic hybridization between navel orange and 'Murcott' tangor. Proc. 6th Intl. Citrus Congr., Middle East 1:23-28.

Kobayashi, S., T. Ohgawara, I. Oiyama, and S. Ishii. 1988b. A somatic hybrid plant obtained by protoplasm fusion between navel orange (Citrus sinensis) and satsuma mandarin (Citrus unshiu). Plant, Cell, Tissue \& Organ Culture 14:63-69.

Menczel, L., F. Nagy, Z. Kiss, and P. Maliga. 1981. Streptomycin resistant and sensitive hybrids of Nicotiana tabacum and Nicotiana knightiana: Correlation of resistance with N. tabacum plastids. Theor. Applied Genet. 59:191-195.

Moore, G.A. and W.S. Castle. 1988. Morphological and isozymic analysis of open-pollinated Citrus rootstock populations. J. Hered. 79:59-63.

Murashige, T. and D.P.H. Tucker. 1969. Growth factor requirements of citrus tissue culture. Proc. First Intl. Citrus Symp. 3:1155-1161.

Nickell, L.G. and J.G. Torrey. 1969. Crop improvement through plant cell and tissue culture. Science 166:1068-1070.

Ohgawara, T., S. Kobayashi, S. Ishii, K. Yoshinoga, and I. Oiyama.

1989. Somatic hybridization in Citrus: Navel orange $(C$. sinensis Osb.) and grapefruit (C. paradisi Macf.). Theor. Applied Genet. 78:609-612.

Ohgawara, T., S. Kobayashi, E. Ohgawara, H. Uchimiya, and S. Ishii. 1985. Somatic hybrid plants obtained by protoplasm fusion between Citius sinensis and Poncirus trifoliata. Theor. Applied Genet. 71:1-4.

Sass, J.E. 1958. Botanical microtechnique. Iowa State Univ. Press, Ames. p. 73-75.
Saunt, J. 1990. Citrus varieties of the world. Sinclair International, Norwich, England.

Soost, R.K. and J.W. Cameron. 1969. Tree and fruit characters of Citrus triploids from tetraploid by diploid crosses. Hilgardia 20:569579.

Swingle, W.T. and P.C. Reece. 1967. The botany of citrus and its wild relatives, p. 190-430. In: W. Reuther, L.D. Batchelor, and H.J. Webber (eds.). The citrus industry. vol. 1. Univ. of California Press, Berkeley.

Torrey, J.G. 1977. Cytodifferentiation in cultured cells and tissues. HortScience 12:138-139.

Tusa, N., J.W. Grosser, and F.G. Gmitter, Jr. 1990. Plant regeneration of 'Valencia' sweet orange, 'Femminello' lemon, and the interspecific somatic hybrid following protoplasm fusion. J. Amer. Soc. Hort. Sci. 115:1043-1046.

Vardi, A., P. Arzee-Gonen, A. Frydman-Shani, S. Bleichman, and E. Galun. 1989. Protoplasm fusion mediated transfer of organelles from Microcitrus and Citrus and regeneration of novel alloplasmic trees. Theor. Applied Genet. 78:741-747.

Vardi, A., A. Breiman, and E. Galun. 1987. Citrus cybrids: Production by donor-recipient protoplast-fusion and verification by mitochondrial-DNA restriction profiles. Theor. Applied Genet. 75:51-58.

Wijbrandi, J., A. Posthuma, J.M. Kok, R. Rijken, J.M. Vos, and M. Koomeef. 1990. Asymmetric somatic hybrids between Lycopersicon esculentem and irradiated Lycopersicon peruvianum. 1. Cytogenetic and morphology. Theor. Applied Genet. 80:305-312. 